\title{
Management of Compound Myopic Astigmatism Using Toric Implantable Collamer Lens after Corneal Collagen Cross linking in Keratoconic Eyes
}

\author{
Jay Sheth, Ananth Doddaramegowda, Mekhla Naik* and Mohd Shahbaaz \\ Lotus Eye Care Hospital, India
}

Submission: June 05, 2017; Published: September 06, 2017

*Corresponding author: Mekhla Naik, Lotus Eye Care Hospital, Coimbatore, Tamil Nadu, India, Tel: 9171764961; Email : mekhlanaik@gmail.com

\begin{abstract}
Context: Correction of compound myopic astigmatism is a challenge in keratoconic eyes post-CXL using traditional approaches such as spectacles and contact lens. Toric Implantable Collamer Lenses (ICL's) are fast emerging as an efficacious treatment modality in such cases.
\end{abstract}

Aim: To analyze the visual outcomes achieved with implantation of Toric Implantable Collamer Lens (ICL) in patients of keratoconus pretreated with Corneal Collagen Crosslinking with Riboflavin (C3R).

Settings and design: Retrospective interventional study

Methods and material: Twelve eyes of seven patients underwent planned toric ICL implantation following 3-6 months post C3R. All surgeries were performed at Lotus Eye Care Institute, Coimbatore, TN, India between October 2009 and August 2011. Follow up examinations were performed at 1 month, 3-6 months and 1 year.

Statistical analysis used: The mean and standard deviation were calculated for the age and follow-up of the patients.

Results: The mean age was 24 years (range 20-30 years). There were 4 female and 3 male patients. Minimum and maximum follow up was 1 month and 30 months respectively. All patients maintained a UCVA of $6 / 9$ or better.

Conclusion: Implantation of a toric ICL in keratoconus patients previously stabilized with C3R is an effective and safe method to provide these patients glass free vision.

Keywords: Keratoconus; Implantable contact lens; Corneal collagen cross linking

Key Messages: Toric ICL is an efficient method for correction of refractive error in keratoconus patients post C3R.

\section{Introduction}

Keratoconus is an ectatic disorder of the cornea that usually manifests during puberty. It is a bilateral, asymmetrical, noninflammatory ectatic disorder that causes conical anterior bulging and thinning of the cornea [1]. This abnormal shape of the cornea causes a steepening which results in a high astigmatism which increases as the disease progresses. This astigmatism can initially be corrected by glasses and contact lenses [2]. In advanced cases with severe myopic astigmatism and corneal opacity the patients become intolerant to contact lenses as fitting becomes difficult or visual acuity may not improve. In this group invasive procedures like penetrating or deep anterior lamellar keratoplasty are required for restoring the visual function [2]. Most of these patients are young and therefore lesser invasive procedures should be considered. Corneal ablative procedures like laser in situ keratomileusis and photorefractive keratectomy are usually contraindicated as they may cause worsening of the disease by causing further thinning of the cornea [3]. Intra stromal corneal ring segments have been used to correct the induced astigmatism and reinforce the cornea but they do not halt the progression of the disease [4]. Corneal collagen crosslinking using riboflavin (C3R) and ultraviolet (UV) light has been increasing used to halt the progression of keratoconus [5]. In our study our primary aim was to provide a glass-free vision to the patient of keratoconus by correcting the refractory error with the means of a toric collamer phakic intraocular lens (toric pIOL) placed in the ciliary sulcus (STAAR surgicals). This procedure was undertaken 3-6 months post-C3R which served to stabilize the myopic astigmatism. 


\section{Subject and Methods}

\section{Study design}

Retrospective interventional study

\section{Study population}

The inclusion criteria were age $\geq 18$ years, best corrected visual acuity (BCVA) of 6/12 or better on Snellen's visual acuity chart, presence of unilateral / bilateral keratoconus as proven on Orb scan and a history of undergone $\mathrm{C} 3 \mathrm{R} \geq 3$ months in the same eye. The exclusion criteria were anterior chamber depth $<2.8 \mathrm{~mm}$, presence of corneal opacity / cataract / macular degeneration, history of ocular hypertension or glaucoma or retinal detachment. Data recovered from the case records of these patients at baseline included age, gender, BCVA with refraction, slit lamp bio microscopy and fundus examination, IOP by Goldmann applanation tonometry, gonioscopy and corneal topography by Orb scan. The patients were followed-up at 1 month, 3-6 months and 1 year. At each follow-up visit, the visual outcome was assessed by means of BCVA with refraction and the safety analysis was performed by noting down any adverse events, anterior and posterior segment examination, vaulting of the toric pIOL, IOP measurements and gonioscopy. Repeat orb scan was done at the end of 1 year follow-up.

\section{Surgical technique}

All patients were operated under topical anesthesia. All patients were dilated with tropicamide plus phenylephrine and cyclopentolate eye drops one hour prior to surgery. A temporal incision was preferred in all cases. The ICL was inserted into the anterior chamber and placed in the sulcus and rotated into the required axis. The pupil was constricted with pilocarpine and a peripheral iridectomy was made. A representative example is shown in Figure 1.

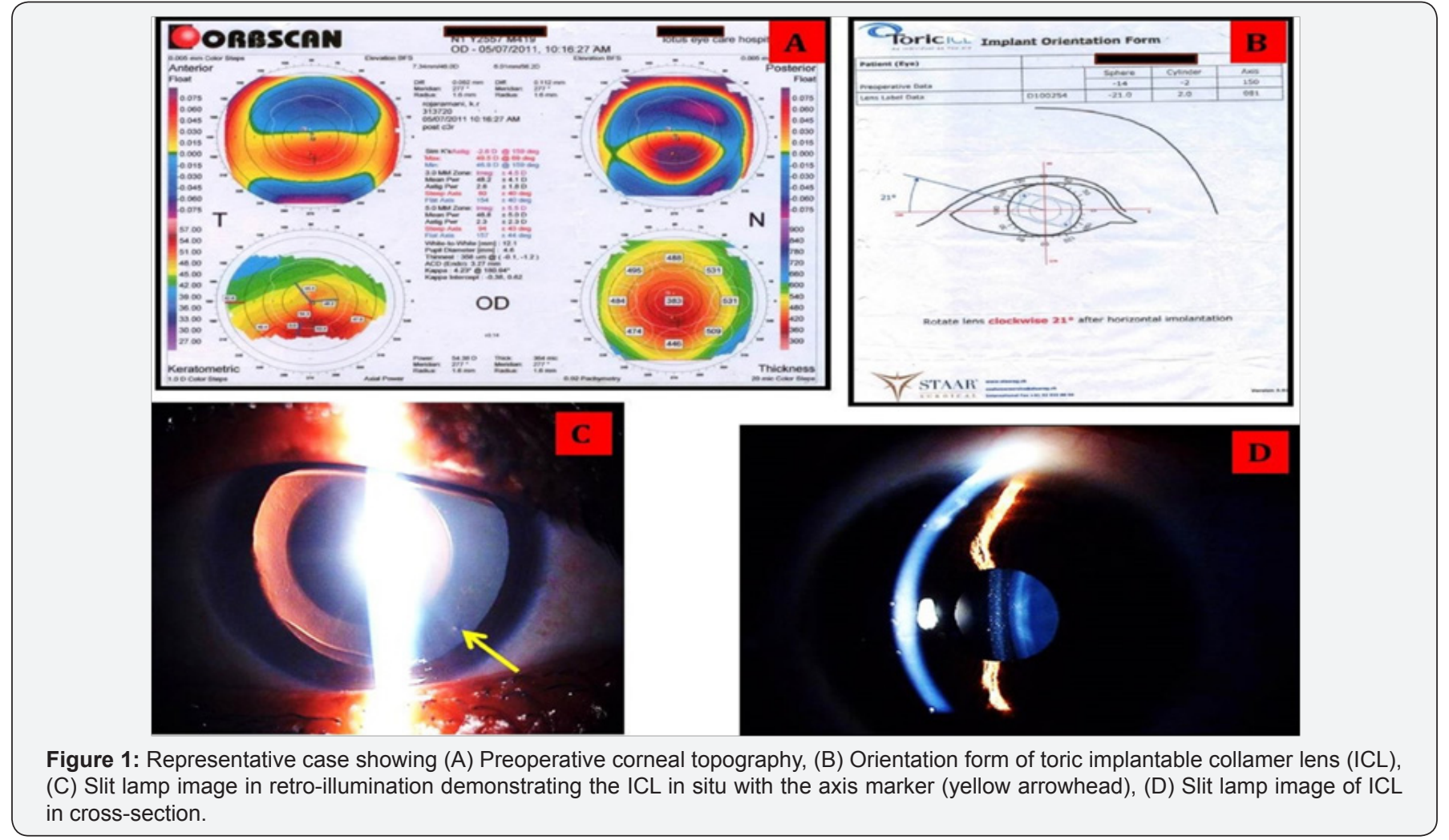

\section{Statistical Analysis}

The mean and standard deviation were calculated for the age and follow-up of the patients.

\section{Results}

Twelve eyes of seven patients were evaluated. Five patients had bilateral implantation and two patients had unilateral implantation. The mean age of the study group was $24 \pm 3.1$ years (Figure 2). There were 4 females and 3 males in the study group. The median follow-up period was 8 months (minimum 1 month, maximum 30 months). All eyes completed the one month follow-up. Six of the twelve eyes completed the 6 month and 12 month follow-up respectively. At the end of one month, all eyes maintained a UCVA of 6/9 or better, with 5 eyes having a UCVA of $6 / 6$ (Table 1 ). Of the six eyes that completed the six month and the one year follow-up, two eyes maintained a UCVA of $6 / 6$ and four eyes maintained a UCVA of $6 / 9$ respectively (Table 2 \& 3). Out of the four eyes with UCVA of $6 / 9$, three eyes had a mean residual spherical equivalent of $+1.25 \mathrm{D}$ and one eye had a residual spherical equivalent of $-1.50 \mathrm{D}$. The mean residual cylindrical power was $-1.25 \pm(-1.54) \mathrm{D}$ for the four eyes. There were no intra- or post-operative complications. No incidence of any rise in IOP, cataract formation or retinal detachment was noted. 


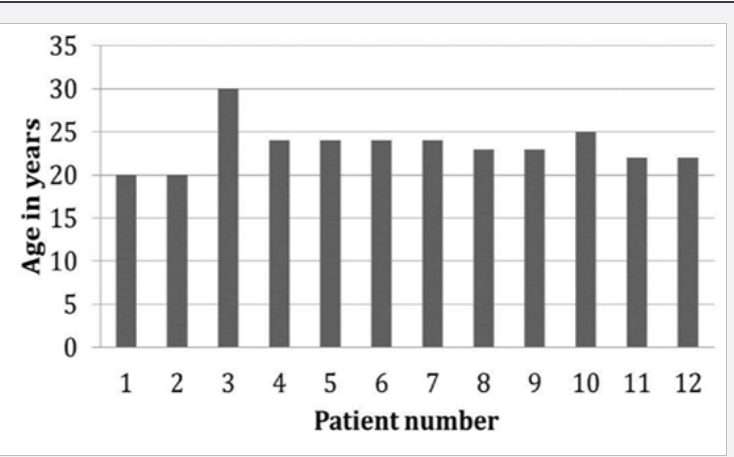

Figure 2: Age Distribution of study group.

Table 1: One month postoperative results of visual outcomes.

\begin{tabular}{|c|c|}
\hline Uncorrected Visual Acuity (UCVA) & No of Eyes \\
\hline $6 / 9$ & 7 \\
\hline $6 / 6$ & 5 \\
\hline
\end{tabular}

Table 2: Six month postoperative results of visual outcomes.

\begin{tabular}{|c|c|}
\hline Uncorrected Visual Acuity (UCVA) & No of Eyes \\
\hline $6 / 9$ & 4 \\
\hline $6 / 6$ & 2 \\
\hline
\end{tabular}

Table 3: Twelve month postoperative results of visual outcomes.

\begin{tabular}{|c|c|}
\hline Uncorrected Visual Acuity (UCVA) & No of Eyes \\
\hline $6 / 9$ & 4 \\
\hline $6 / 6$ & 2 \\
\hline
\end{tabular}

\section{Discussion}

The purpose of our study was to analyze whether toric pIOL's could be used safely to correct myopic astigmatism which was stabilized by C3R in patients with keratoconus. The assessment of our data has shown satisfactory visual and safety outcomes. The predictability was very good as at the end of one year, two eyes were emmetrope, and four eyes had a mean residual cylindrical power of $-1.25 \pm(-1.54) \mathrm{D}$ and mean residual spherical equivalent of $+1.25 \mathrm{D}$ ( 3 eyes) and $-1.50 \mathrm{D}$ (1 eye) respectively. To our knowledge, there have been only two studies that have analyzed the efficacy of toric pIOL in patients of keratoconus [6,7]. Alfonso et al. [6], have reported good stability and predictability with toric pIOL in patients of keratoconus for 12 months. Many other studies have been done to treat the refractive error of keratoconus by means of spherical anterior chamber pIOLs [8], iris fixated pIOLs [9], anterior and posterior chamber toric IOL's [10] as well as by refractive lens exchange [11] and multifocal IOL's [12]. Of all these, only the refractory lens exchange and multifocal IOL's have shown good results.

Phakic IOL's have been associated with complications like anterior sub capsular cataracts and increased IOP [13,14]. In our study though, we did not report any incidence of adverse event till the end of one year. However, one year may be a short duration of follow-up to evaluate the refractive stabilization as well as to gauge the development of any adverse reactions. This is one of the short-coming of our study. In conclusion, our results show that toric pIOL's can be used safely and predictably to correct the refractive error in keratoconus patients once the power has been stabilized by means of C3R. We recommend longer follow-up of the patient for at least 3-5 years along with a larger sample size to propose guidelines for refractive correction of keratoconus patients.

\section{References}

1. Mahadevan R, Arumugam AO, Arunachalam V, Kumaresan B (2009) Keratoconus - a review from a tertiary eye-care center. J Optom 2(4): 166-172.

2. Gordon MO, Steger MK, Szczotka FL, Riley C, Joslin CE, et al. (2006) Baseline factors predictive of incident penetrating keratoplasty in keratoconus. Am J Ophthalmo 142: 923-930.

3. Schmitt BCFM, Lesage C, Arnaud B (2000) Keratectasia induced by laser in situ keratomileusis in keratoconus. J Refract Surg 16: 368-370.

4. Colin J (2006) European clinical evaluation: use of Intacs for the treatment of keratoconus. J Cataract Refract Surg 32(5): 747-755.

5. Wollensak G, Spoerl E, Seiler T (2003) Riboflavin/ultraviolet-Ainduced collagen cross linking for the treatment of keratoconus. Am J Ophthalmol 135(5): 620-627.

6. Alfonso JF, Fernández VL, Lisa C, Fernandes P, González MJM, et al. (2010) Collagen copolymer toric posterior chamber phakic intraocular lens in eyes with keratoconus. J Cataract Refract Surg 36(6): 906-916.

7. Kamiya K, Shimizu K, Ando W, Asato Y, Fujisawa T (2008) Phakic toric Implantable Collamer Lens implantation for the correction of high myopic astigmatism in eyes with keratoconus. J Refract Surg 24(8): 840-842.

8. Leccisotti A, Fields SV (2003) Angle-supported phakic intraocular lenses in eyes with keratoconus and myopia. J Cataract Refract Surg 29(8): 1530-1536.

9. Budo C, Bartels MC, van Rij G (2005) Implantation of Artisan toric phakic intraocular lenses for the correction of astigmatism and spherical errors in patients with keratoconus. J Refract Surg 21(3): 218-222.

10. Kamburog lu G, Ertan A, Bahadır M (2007) Implantation of Artisan toric phakic intraocular lens following Intacs in a patient with keratoconus. J Cataract Refract Surg 33(3): 528-530.

11. Leccisotti A (2006) Refractive lens exchange in keratoconus. J Cataract Refract Surg 32(5): 742-746.

12. Ferna'ndez VL, Alfonso JF, Rodríguez PP, Monte's MR (2007) Clear lens extraction with multifocal apodized diffractive intraocular lens implantation. Ophthalmology 114(8): 1491-1498.

13. Sanders DR, Vukich JA (2002) Incidence of lens opacities and clinically significant cataracts with the Implantable Contact Lens: comparison of two lens designs. J Refract 18(6): 673-682.

14. Chung TY, Park SC, Lee MO, Ahn K, Chung ES (2009) Changes in iridocorneal angle structure and trabecular pigmentation with STAAR Implantable Collamer Lens during 2 years. J Refract Surg 25(3): 251258. 
This work is licensed under Creative Commons Attribution 4.0 License DOI: $10.19080 /$ JOJO.2017.04.555640
Your next submission with Juniper Publishers will reach you the below assets

- Quality Editorial service

- Swift Peer Review

- Reprints availability

- E-prints Service

- Manuscript Podcast for convenient understanding

- Global attainment for your research

- Manuscript accessibility in different formats

( Pdf, E-pub, Full Text, Audio)

- Unceasing customer service

Track the below URL for one-step submission https://juniperpublishers.com/online-submission.php 